\title{
CARTAS DA RESISTÊNCIA: TRADUÇÃO, BIOGRAFIA E HISTÓRIA
}

\author{
Anna Carolina Schäfer ${ }^{1}$ \\ Juliana Pasquarelli Perez 1 \\ ${ }_{1}^{1}$ Universidade de São Paulo, São Paulo, São Paulo, Brasil \\ Tinka Reichmann ${ }^{2}$ \\ ${ }^{2}$ Universidade de Leipzig, Leipzig, Alemanha
}

\begin{abstract}
Resumo: A resistência alemã ao nacional-socialismo, tema ainda pouco difundido e estudado no contexto brasileiro, é associada sobretudo a nomes de indivíduos que agiram sozinhos ou junto a grupos estabelecidos a partir de círculos de afinidade e confiança. As cartas escritas entre 1933 e 1945 por Helmuth James von Moltke e por outros opositores do nacional-socialismo trazem à tona a dimensão biográfica da resistência, ao evidenciarem, em textos autênticos, as experiências individuais que levaram cada um deles a entrar em conflito com o regime. Tendo isso em vista, o presente trabalho analisa a interface entre as dimensões subjetiva e histórica em uma seleção de cartas e aborda a relação entre os papeis do tradutor e do editor na transposição dessas cartas para o português. A tradução das cartas pode contribuir para a difusão, em contexto brasileiro, do tema da resistência alemã ao nacional-socialismo.
\end{abstract}

Palavras-chave: Resistência Alemã; Nacional-Socialismo; Cartas; Tradução; Moltke

\section{LETTERS OF RESISTANCE: TRANSLATION, BIOGRAPHY AND HISTORY}

Abstract: The German resistance to National Socialism is a topic which is not very well-known or studied in the Brazilian context and is predominantly associated with the names of individuals who acted on 
their own or within groups that were composed of like-minded people and confidants. The letters written between 1933 and 1945 by Helmuth James von Moltke and by several other opponents of National Socialism illustrate the biographic dimension of resistance. They reveal, in authentic texts, individual experiences that motivated each opponent to start conflict with the regime. With that in mind, the present work analyses the interface between the subjective and the historic dimension within a selection of letters and discusses the roles of the translator and the editor when transferring them into Portuguese. The translation of these letters can contribute to the dissemination, within the Brazilian context, of the topic "German resistance to National Socialism".

Keywords: German Resistance; Nacional Socialism; Letters; Translation; Moltke

\section{Quando a tradução reconta mais uma história}

"Quando a tradução (re)conta a história" é o título de uma das pesquisas feitas no Brasil sobre o grupo de resistência conhecido como $A$ rosa branca ( $C f$. Schäfer). O título poderia servir para vários outros trabalhos sobre a resistência alemã ao nazismo. A história d'A rosa branca, cujos membros redigiram e distribuíram panfletos contra o regime nacional-socialista entre 1942 e 1943, tornou-se conhecida na Alemanha a partir do relato de Inge Scholl, irmã de dois integrantes do grupo. A primeira edição do livro na Alemanha é de 1952; nos anos 90 o relato foi ampliado e se tornou um pequeno best-seller, embora tenha sido criticado muitas vezes por omitir a importância de outros membros do grupo e também por ser impreciso do ponto de vista histórico. De fato, os documentos conhecidos hoje e as pesquisas feitas sobre a resistência alemã ao nacional-socialismo relativizam muitos pontos do relato de Inge Scholl; e o trabalho da Weiße Rose Stiftung (Fundação Rosa Branca) tem sido fundamental para divulgar e preservar a memória dos outros participantes do grupo e para incentivar estudos sobre o tema. Lido hoje de forma mais adequada como homenagem pessoal de Inge Scholl a seus irmãos, o livro $A$ rosa branca ainda cumpre 
a função de oferecer a jovens leitores o primeiro contato com a história da resistência alemã ao nazismo.

No Brasil, por exemplo, antes que sua tradução fosse publicada mal se conhecia a história dos participantes d'A rosa branca e pouco se falava da existência de grupos alemães de resistência ao regime nacional-socialista. Nem mesmo o lançamento do filme de Marc Rothemund, Sophie Scholl - Die letzten Tage (traduzido no Brasil como Uma mulher contra Hitler), em 2005, colocou o tema em debate: embora tenha recebido vários prêmios internacionais, por aqui o filme foi recebido com uma dura crítica na Folha de São Paulo (Cf. Araújo); outra resenha, publicada em $O$ Estado de São Paulo, ressalta o talento da atriz que representa Sophie Scholl, mas nem mesmo menciona a existência de um grupo de resistência. ${ }^{1}$ Seria difícil estimar quantas pessoas conhecem hoje a história $d$ ' $A$ rosa branca no Brasil, mas ao menos se sabe que quatro mil exemplares do livro foram vendidos e que ele foi reimpresso em $2020 .^{2}$

Desde que a tradução foi publicada, também surgiram no meio acadêmico alguns estudos sobre o tema: os trabalhos de Schäfer (2015), Salgado (2017) e Utida (2017) tratam, respectivamente, dos interrogatórios de Hans e Sophie Scholl, do documentário Die Widerständigen [Os resistentes], de Katrin Seybold, e dos depoimentos de Franz Müller e Hans Hirzel no Bundestag [Parlamento alemão], em 1984. Todos os materiais correspondentes foram traduzidos, o que novamente tornou acessível ao público interessado material histórico inédito no Brasil. Sales (2017) analisou as ações do grupo do ponto de vista histórico, e Alonso (2019) tratou de mo-

${ }^{1}$ Outro filme importante sobre o tema, o longa-metragem de Michael Verhoeven (Die Weiße Rose, 1982) reabriu a discussão sobre a legalidade dos processos nazistas na Alemanha, mas não teve tradução para o português e é dificilmente acessível no Brasil. A tradução de cartas e anotações de Dietrich Bonhoeffer (2003) foi publicada em 2003, mas seu alcance parece ter ficado mais restrito a interessados em teologia.

${ }^{2}$ A edição de 2013 teve tiragem de dois mil exemplares, que se esgotaram rapidamente. A segunda edição, também com dois mil exemplares, foi publicada em 2014, corrigiu pequenas falhas da primeira e é a base da reimpressão feita em 2020. No total, foram impressos seis mil exemplares do livro. 
vimentos antinazistas que surgiram entre os imigrantes, exilados e refugiados de língua alemã no Brasil.

Assim, é possível dizer que a tradução do livro de Inge Scholl não apenas trouxe à tona uma gama de materiais a serem traduzidos e divulgados a respeito da resistência alemã ao nazismo $(C f$. Reichmann, Schäfer, Salgado), como também ampliou a discussão sobre o próprio conceito de resistência. Afinal, o que significava "resistir" e quais foram os modos possíveis de resistência durante o nacional-socialismo? De fato, o termo "resistência" costuma ser associado mais facilmente à França ou a outros países sob a ocupação nazista do que a alemães que se opunham ao regime $(C f$. Rollemberg 80). Entretanto, houve vários grupos de resistência na Alemanha, ${ }^{3}$ embora não se deva imaginar sob o termo apenas ações como o atentado a Hitler ou tentativas concretas de derrubar o regime. No contexto do nacional-socialismo, "resistir" possui sentido mais amplo:

\begin{abstract}
Martin Broszat classificou como 'resistência' todas as formas de 'rejeição, limitação e restrição efetivas ao regime nacional-socialista ou aos seus objetivos, independentemente da motivação, da justificativa ou da convicção individual' de cada um. Ian Kershaw usa o termo 'dissensão' para designar as formas menos espetaculares de resistência. [...] É importante destacar que mesmo ações que, do ponto de vista atual, não seriam caracterizadas como resistência eram combatidas como tais pela Gestapo e de maneira sempre mais ampla, numa crescente radicalização da violência. (Hudemann 250). ${ }^{4}$
\end{abstract}

\footnotetext{
3 Por não ser possível aqui fazer uma listagem de todos os grupos, o texto tratará, além d'A rosa branca, sobretudo do grupo conhecido como Círculo de Kreisau [Kreisauer Kreis].

${ }^{4}$ Também é preciso recordar que, em regimes democráticos, algumas das formas de protesto utilizadas por membros dos grupos de resistência seriam vistas hoje como ações de desobediência civil. $C f$. a tese de doutorado em andamento de Eraldo Santos, também um dos tradutores do livro A rosa branca, sobre o conceito de desobediência civil em contraposição à resistência. A tese será defendida em 2021
} 
Hans Mommsen observa que atualmente é consenso entre os pesquisadores do tema não julgar a resistência a partir do êxito que os movimentos ou iniciativas tenham obtido - uma vez que se sabe que as chances de sucesso eram poucas ou nenhuma. $\mathrm{O}$ historiador ainda acrescenta que a resistência tampouco deve ser observada apenas na sua dimensão moral, embora seja fundamental recordar que, diante da possibilidade de acusação de "alta traição" - portanto, diante do risco de morte que as ações de resistência traziam - os objetivos e interesses políticos talvez tivessem para os resistentes um valor secundário em comparação à questão moral. Assim, segundo Mommsen, para estudar adequadamente a história da resistência alemã, deve-se considerar tanto questões pessoais quanto motivações e objetivos políticos dos conspiradores, mudanças internas do regime nazista e pressupostos políticos, ideológicos e sociais originados no período da República de Weimar. ${ }^{5}$

Devido a tal herança, na história dos grupos de resistência observam-se desde possibilidades de oposição mais ou menos compatíveis com o regime, com atenuação de atitudes mais radicais, até tentativas de derrubada do regime ( $C f$. Mommsen 31). Não deve espantar, portanto, que entre seus participantes se encontrem pes-

na Sorbonne, título provisório: La désobéissance civile: Un essai de généalogie conceptuelle, 1935-1975.

5 "Es besteht Einigkeit darüber, daß der Widerstand nicht an Kategorien des äußeren Erfolges gemessen werden kann. Vielmehr lehren die Erfahrungen mit Diktaturen in unserer Gegenwart wie eine genauere Kenntnis der Kampfbedingungen der Verschwörer, daß die Chancen verschwindend gering waren, das Regime von innen heraus zu Fall zu bringen. Die Betrachtung des Widerstands darf sich andererseits nicht in der Herausarbeitung seiner moralischen Dimension erschöpfen, wenngleich uns die Formel vom 'Aufstand des Gewissens' zu Recht daran erinnert, daß Handeln in der Grenzsituation des bewußten Hochverrats tiefere ethische Bindungen zur Voraussetzung hatte, der gegenüber politischen Interessen und soziale Motive zweitrangig waren. Denn ein wirkliches Verständnis und eine angemessene Bewertung des Widerstands ist nur dann möglich, wenn die politischen Antriebe und Zielsetzungen der Verschwörer zusammen mit der sich verändernden Gesamtsituation des Regimes wie den in die Zeit der Weimarer Republik zurückreichenden gesellschaftspolitischen und ideengeschichtlichen Voraussetzungen in den Blick genommen werden." (Mommsen 30).

Cad. Trad., Florianópolis, v. 41, no 3 p. 242-272, set-dez, 2021. 
soas tão diversas como membros da elite militar da época, intelectuais de perfil que hoje denominaríamos "conservador" e lideranças políticas de esquerda. Tampouco surpreende que em alguns escritos políticos e pessoais (como cartas, anotações e diários) dos resistentes haja tanto referências a um ideário patriótico-nacionalista como reflexões de cunho existencial e religioso. A mescla de diversos temas e níveis de reflexão é constante, como se verifica nos panfletos distribuídos pelos estudantes de Munique, nas recordações dos sobreviventes ( $C f$. Utida) e em suas cartas. Importa ressaltar que também houve ações de resistência por parte dos judeus nos guetos e nos campos de concentração, situação extrema que exige outras formas de se pensar o conceito de resistência. ${ }^{6}$

Outro aspecto que caracteriza a resistência alemã é o isolamento em que se encontravam as pessoas que se colocavam contra o regime: conscientes do poder da máquina de propaganda nazista e, como se mencionou, do risco de serem acusadas de alta traição, os resistentes agiam individualmente ou apenas em pequenos grupos. Neste sentido, pode-se dizer que a resistência alemã se caracteriza por não ter sido um movimento coeso e organizado, mas por ser sobretudo obra de indivíduos ( $C f$. Klemperer 7), sendo associada a nomes de pessoas que agiram sozinhas, como Georg Elser, responsável pelo atentado à bomba contra Hitler em uma cervejaria de Munique em 1939, ou a grupos relativamente pequenos, formados em geral a partir de círculos de amizade e confiança, como no caso d'A rosa branca ou do Círculo de Kreisau, liderado por Helmuth James von Moltke. A passagem de uma crítica discreta e parcial a alguma atividade de resis-

${ }^{6} \mathrm{O}$ artigo não tem o objetivo de tratar de todos os grupos de resistência que existiram na Alemanha, apenas menciona alguns deles para melhor localizar as cartas que serão traduzidas e o papel da tradução para um conhecimento mais amplo do tema no Brasil. É importante destacar, porém, alguns grupos judaicos de resistência, como o Jüdischer Kulturbund, citado mais adiante por Petrescu; a Jüdische Kampforganisation [Żydowska Organizacja Bojowa, abreviado ŻOB, em iídiche: Jidische Kamf Organisatie] que atuou na Polônia sob a ocupação nazista, e o chamado Grupo Herbert Baum. Cf. a respeito os estudos de Barbara Distel (2008) e John Cox (2009). 
tência só pode ser dada por aqueles que encontraram apoio em outra forma de utopia política ${ }^{7}$, de agrupamento social ou de experiência religiosa $^{8}$, e que assim possuíam alguma experiência de enraizamento ou pertença, nos termos de Simone Weil, mais importante do que o agrupamento ideológico proposto pelo regime hitlerista.

Na pesquisa de Corina Petrescu sobre "Modelos de espaços subversivos no nacionalsocialismo", tais grupos teriam um espaço de discussão "cripto-público", que ela define como "esfera privada politizada" e "esfera potencial para o ativismo contrário ao estado" ["the space of the crypto-public - defined as a politicized private sphere, as a potential sphere for anti-state activism."] (Petrescu 1). Petrescu ainda observa que espaços cripto-públicos conseguiram reunir pessoas com convicções similares e ofereceram a possibilidade de resistir à ideologia do regime, ainda que não tenham garantido nenhuma ação concreta de oposição, compreendida como uma ação destinada a derrubar o regime:

7 "Es leuchtet daher ein, daß der Schritt von der Teilkritik am nationalsozialistischen System zum Widerstand nur von Personen getan werden konnte, die, wie die Kommunisten und Linkssozialisten, aus starken ideologischen und politischen Bindungen heraus dem Druck des Hitler-Mythos widerstanden oder die aufgrund ihrer gesellschaftlichen Herkunft und Stellung, zugleich eines autochthonen Nationalbewußtseins beziehungsweise einer Gegenutopie sich, in unterschiedlichem Maße, diesem psychologischen Zwang zu entziehen vermochten.” (Mommsen 34).

8 "Christentum, Rechtsstaatsgedanke und Korruptionsfreiheit der öffentlichen Verwaltung waren angesichts der extremen Mißständen im Dritten Reich gewichtige und ernst zu nehmende Zielsetzungen der Verschwörer, die dafür ihr Leben eingesetzt und hingegeben haben. Aber die konkreten Vorschläge, diesen Wertvorstellungen Durchsetzungen zu verschaffen, muten doch vergleichsweise realitätsfremd an, zumal sie ausdrücklich mehr als Eventualplanungen darstellten. Diese Feststellung kann nicht als politisch-moralische Abwertung des nationalkonservativen Widerstandes betrachtet werden. Es ist nicht leicht, sich einzugestehen, daß der Nationalsozialismus oder doch Teile der Ziele, für die er stand, so tief in das Denken und das Handeln der deutschen Massen eingedrungen waren, daß nur aus letztlich utopisch bestimmten und tief religiösem Denken heraus Widerstandskräfte mobilisiert werden konnten, während pragmatisch denkenden Politiker wie Konrad Adenauer oder Theodor Heuss in Resignation verfielen oder gar keinen Ansatzpunkt zu realistischen Handeln erblicken zu können glaubten.” (id. 42). 
[...] This latter public domain, which I call crypto-public, brings together people of similar convictions and may mobilize them into a front that stands in disagreement with the state, yet ultimately remains isolated and confined, both in its actions and importance, to the small group of initiators. This space offers the possibility to resist, i.e. withstand, the state, but offers no guarantee that acts of opposition will emerge from it. In order for actions occurring within it to become opposition, they must undermine the entire power structure of the opposed system and strive for the abolition of the regime. (Petrescu 3). ${ }^{9}$

A tradução de documentos propriamente políticos, como no caso de panfletos, e de outros materiais históricos, como protocolos e peças jurídicas, relativos aos círculos de opositores ao regime nazista é, como se mencionou, um campo que apenas começou a ser explorado. Dentre os diversos materiais que podem ser traduzidos, quando se pensa no entrelaçamento entre crenças e opiniões pessoais, visões políticas herdadas de um certo contexto sociocultural, experiências cotidianas, encontros com membros da resistência de outros grupos, destaca-se um gênero de textos especialmente fascinante: a carta. Há uma ligação concreta, por exemplo, entre o círculo Scholl-Schmorell e Helmuth von Moltke: por meio das relações de Moltke, após a execução de Hans e Sophie Scholl e Christoph Probst, o último panfleto d'A rosa branca chegou clandestinamente ao Reino Unido - e foi lançado aos milhares por aviões britânicos sobre a cidade de Munique, em julho de 1943. Mas é na correspondência dos membros dos diversos grupos que se percebem tanto a diferença nos graus de organização de cada círculo quanto as similaridades do ponto de vista da experiência humana.

\footnotetext{
${ }^{9}$ Dentre os movimentos de resistência, Petrescu estuda três espaços fundamentais: o gueto, como esfera pública, no caso da Jüdischer Kulturbund [Federação Cultural Judaica]; uma esfera de contraposição passiva, no caso do Círculo de Kreisau e uma esfera de contraposição ativa ao regime, no caso d'A rosa branca - que Petrescu, seguindo outros autores, chama de Schmoll-Schmorell-Kreis e Schulze-Boysen/Harnack Organisation. (Cf. Petrescu 2).
} 
A tradução de cartas de membros da resistência oferece uma visão surpreendente do significado particular de resistir e de suas consequências sociais. São documentos pessoais e documentos históricos que exigem do tradutor não apenas conhecimento histórico e uma sensibilidade especial para o estilo de cada missivista, mas também decisões sobre a seleção das cartas a serem traduzidas e a forma de sua apresentação aos leitores brasileiros. Cabe aqui, agora, uma breve consideração sobre o gênero.

\section{Sobre o gênero "carta"}

As cartas de Helmuth James von Moltke - como a de outros membros da resistência - não causam nenhuma dúvida quanto à sua função: trata-se da correspondência entre familiares ou amigos, escrita sem pretensões estéticas, muitas vezes com intuito de informar o destinatário sobre a situação atual do remetente. Do ponto de vista da estrutura tampouco há inovação formal: à saudação mais ou menos informal do destinatário seguem-se referências a cartas anteriores, agradecimentos, notícias sobre o dia-a-dia, menção a amigos, algum comentário jocoso, recomendações ou perguntas sobre pessoas conhecidas e uma formulação de despedida. ${ }^{10}$

Ao mesmo tempo, esse tipo de missiva pertence a uma longa tradição: em seu capítulo "A escrita de si”, que aborda tanto os chamados hypomnemata ${ }^{11}$ (registros e anotações que, ao longo do

${ }^{10}$ A tradução de cartas de Moltke faz parte de um projeto mais amplo, que inclui também cartas de outros membros da resistência alemã.

11 "Na sua acepção técnica, os hypomnemata podiam ser livros de contabilidade, registos notariais, cadernos pessoais que serviam de agenda. $\mathrm{O}$ seu uso como livro de vida, guia de conduta, parece ter-se tornado coisa corrente entre um público cultivado. Neles eram consignadas citações, fragmentos de obras, exemplos e acções de que se tinha sido testemunha ou cujo relato se tinha lido, reflexões ou debates que se tinha ouvido ou que tivessem vindo à memória. Constituíam uma memória material das coisas lidas, ouvidas ou pensadas; ofereciam-nas assim, qual tesouro acumulado, à releitura e à meditação ulterior. [...] Por mais pessoais que sejam, estes hypomnemata não devem porém ser entendidos como diários 
tempo, serviram como meio de organização do pensamento e como ponto de partida para meditações) quanto a correspondência, Foucault recorda que esta também é lugar de um "exercício pessoal”. É curioso observar que, embora ele se refira à tradição epistolar latina (os escritos de Sêneca, p. ex.), há características do gênero que sofrem poucas variações ao longo do tempo.

A ideia de que conselhos, exortações ou consolações dirigidos ao destinatário também ajudam o próprio remetente a "treinar a si mesmo" (id., 147), por exemplo, permanece. Tampouco parecem ter se perdido a necessidade de um estilo "simples, livre na composição, despojado" (id., 151), como expressão da subjetividade do autor, e a permissão dada ao outro para percorrer os caminhos interiores de quem escreve. Foucault acrescenta ainda que dois grandes temas costumam prevalecer nas cartas: "as interferências da alma e do corpo (mais as impressões que as acções) e os lazeres (mais do que os acontecimentos externos); o corpo e os dias" (id., 153), ou seja, notícias de saúde (sensações corpóreas, mal-estar, ou sua recuperação) e o relato do cotidiano. ${ }^{12}$ Tais características

íntimos, ou como aqueles relatos de experiências espirituais (tentações, lutas, fracassos e vitórias) que poderão ser encontrados na literatura cristã ulterior. Não constituem uma 'narrativa de si mesmo'; não têm por objectivo trazer à luz do dia as arcanas conscientiae cuja confissão - oral ou escrita - possui valor de purificação. O movimento que visam efectuar é inverso desse: trata-se não de perseguir o indizível, não de revelar o que está oculto, mas, pelo contrário, de captar o já dito; reunir aquilo que se pôde ouvir ou ler, e isto com uma finalidade que não é nada menos que a constituição de si." (Foucault 135s).

${ }^{12}$ Foucault resume assim a sua visão desse tipo de "escrita de si": "Mas também nos é possível avaliar o quanto este procedimento da narrativa de si na quotidianeidade da vida, com uma meticulosíssima atenção àquilo que se passa no corpo e na alma, é diferente tanto da correspondência ciceroniana como da prática dos hypomnemata, recolha de coisas lidas e ouvidas, e suporte dos exercícios de pensamento. Num caso - o dos hypomnemata - tratava-se de se constituir a si próprio como sujeito de acção racional pela apropriação, a unificação e a subjectivação de um ‘já dito' fragmentário e escolhido; no caso da notação monástica das experiências espirituais, tratar-se-á de desentranhar do interior da alma os movimentos mais ocultos, de maneira a poder libertar-se deles. No caso da narrativa epistolar de si próprio, trata-se de fazer coincidir o olhar do outro e aquele que se volve 
manifestam-se nas cartas de Sophie e Hans Scholl, por exemplo, e também nas de Moltke. Sophie Scholl, por exemplo, relata banhos de lago e o cotidiano da escola; Hans, aos 19 anos, faz alusão aos grupos de que participou e conta que foi ao cinema; nas cartas de Moltke anteriores à sua prisão se discutem a educação dos filhos, a organização das reservas de alimentos, o frio e a falta de aquecimento no apartamento em Berlim.

Por outro lado, embora o gênero acolha relatos do cotidiano, passe a impressão de espontaneidade e apresente marcas de oralidade, a carta não é uma substituição do discurso oral: a simulação de diálogo com um interlocutor ausente é mediada pela escrita. ( $C f$. Beltrán Almería). Junte-se a isso o fato de que Moltke, jurista, pode ser considerado herdeiro de uma cultura letrada que, a partir de meados do século 18, reconhece na carta um meio de expressão e quase confissão de sentimentos, pensamentos íntimos e convicções ( $C f$. Müller 81). ${ }^{13}$ Nessa mesma época, reforça-se a escrita de cartas de despedida, ${ }^{14}$ que cumprem um papel especial no corpus das cartas de membros da resistência alemã.

para si próprio quando se aferem as acções quotidianas às regras de uma técnica de vida." (id., 160).

${ }^{13}$ No século 18, o gênero não apenas floresceu entre no âmbito da burguesia, mas também encontrou uma contrapartida ficcional - o romance epistolar - que, por sua vez, teve efeito sobre a correspondência no mundo factual. ( $C f$. Müller)

14 "'Briefe schreiben fingiert Lebendiges im Medium des erstarrten Worts", heißt es bei Theodor W. Adorno. ,Im Brief vermag man die Abgeschiedenheit zu verleugnen und gleichwohl der Ferne, Abgeschiedene zu bleiben. 'Eine besondere Blüte erlebte diese gattungstypische Rhetorik von simulierter Anwesenheit und Unmittelbarkeit im 18., dem Jahrhundert des Briefes. Allerdings veränderte sich deren Qualität, wenn sich das temporäre, vielleicht gesuchte, in ein endgültiges Abgeschiedensein verwandelte, wenn es die Trennung von der Welt bedeutete, ein Brief der letzte sein sollte - ein Abschiedsbrief. Dieser Begriff meint hier ausschließlich Botschaften, die ein Mensch bewusst, motiviert durch das Bevorstehen seines eigenen Todes an Verwandte, Freunde oder die Nachwelt allgemein verfasst. Abschiedsbriefe markieren vielfache, miteinander durch die spezifischen Umstände des Verfassens sowie die Bedingungen des Mediums verknüpfte Grenzüberschreitungen: zwischen Leben und Tod, Kommunizieren und Verstummen, Sprechen und Schreiben, Anwesenheit und Abwesenheit.” (Schlinzig 1). 
Assim, na correspondência de membros da resistência entrecruzam-se diversos aspectos socioculturais importantes: aspectos discursivos que caracterizam o gênero epistolar, a acentuação da subjetividade dada pela tradição de escrita do século 18 , o contexto do nacional-socialismo e as condições histórico-sociais em que as cartas de Helmut von Moltke foram escritas. Não é, portanto, no conteúdo isolado de cada carta, nem em sua estrutura particular, nem apenas na personalidade de seus autores que reside o interesse por sua tradução: é a junção tantos elementos significativos num gênero textual tão breve que a torna um desafio de tradução.

Talvez as cartas trocadas entre Helmut e Freya von Moltke não fossem mais que um documento interessante para seus familiares, se nenhum deles tivesse participado da resistência alemã. Lidas em perspectiva histórica, elas documentam o amadurecimento de decisões que definiram o destino de Moltke: da insatisfação incipiente com o regime nazista, passando pela indignação com os crimes que começavam a se tornar conhecidos, pela formulação cuidadosa das notícias e ideias que poderiam ser lidas pelos censores, até a decisão de se colocar contra o nazismo, com total consciência de que tal passo poderia ser fatal.

As cartas de despedida talvez sejam, nesse conjunto, os textos mais impressionantes do ponto de vista existencial: escritas momentos antes da execução de seus autores, reúnem e revelam amor e preocupação com os familiares e amigos e pedido de desculpas pelo sofrimento causado a eles, confissão de fé, reafirmação das convicções políticas e decisões tomadas, desejo de alegrias futuras, desejo de consolo. Nesse sentido, confirmam as características presentes nesse gênero de carta desde o século 18 (Cf. Schlinzig). Escritas no contexto de um regime totalitário, porém, mostram ainda a intenção de não comprometer politicamente os destinatários das cartas e de preservar a própria memória. Podem ser consideradas, conforme afirma Diaz (57), "documento sociológico, mas antes de tudo documento humano porque, muito mais do que em suas obras, é em sua correspondência que se pode perceber a verdade de um homem [...]". 


\subsection{Cartas de Helmuth James Graf von Moltke à Freya von Moltke}

"Iremos para a forca por termos pensado juntos" (Wir werden gehenkt, weil wir zusammen gedacht haben) foi o que afirmou Helmuth James von Moltke a Freya, sua esposa, em uma carta escrita do presídio de Tegel, em Berlim, dias após o julgamento em que foi condenado à morte por ter promovido, junto a um círculo de amigos, discussões contra o regime nacional-socialista. Moltke é considerado hoje um dos nomes emblemáticos da resistência alemã ao nacional-socialismo e é tema de diversas obras e biografias publicadas na Alemanha desde o fim da Segunda Guerra. Duas publicações alemãs relativamente recentes (Oppen; Moltke \& Moltke) reúnem cartas trocadas entre o casal a partir de 1939, quando ambos começam a expressar de maneira mais evidente sua insatisfação pessoal e suas críticas em relação aos rumos tomados pela Alemanha sob o governo de Hitler. A correspondência segue até janeiro de 1945, quando Moltke é executado pelo regime.

O chamado Círculo de Kreisau se formou a partir de $1940 \mathrm{em}$ torno dos casais Helmuth James e Freya von Moltke e Peter e Marion Yorck von Wartenburg. Foi denominado assim pela polícia secreta nazista, a Gestapo, pois muitas de suas reuniões ocorriam na propriedade rural de Moltke situada no vilarejo de Kreisau, região da Silésia. Os amigos Moltke e Yorck almejavam o fim do Estado totalitário, da ideologia racial e da violência do Estado por meio do restabelecimento pacífico da legalidade e consideravam, para isso, a possibilidade de uma "revolução vinda de cima" ( $C f$. Mommsen, "Bürgerlicher (nationalkonservativer) Widerstand", 61), que partisse das camadas mais abastadas e intelectualizadas da sociedade, como medida emergencial para destituir Hitler do poder e colocar fim à guerra.

O Círculo de Kreisau compunha-se de cerca de 40 pessoas advindas de diferentes esferas políticas e sociais. Dentre elas estavam, além dos condes Moltke e Yorck, outros descendentes da nobreza prussiana, políticos e simpatizantes do então extinto Partido So- 
cialdemocrata Alemão (Sozialdemokratische Partei Deutschlands - SPD) como Adolf Reichwein, Carlo Mierendorff e Julius Leber, e os padres jesuítas Alfred Delp, Lothar König e Augustin Rösch. O grupo reunia-se em diferentes formações em Kreisau, Berlim e Munique, com o objetivo de estabelecer, a partir de discussões e reflexões conjuntas, os fundamentos de uma "nova ordem" espiritual, social e econômica que deveria ser implantada na Alemanha com o fim da guerra ( $C f$. Stuiber 607).

O ponto de partida para os debates do grupo foi um escrito de Moltke, redigido no verão alemão de 1940 e intitulado Ueber die Grundlagen der Staatslehre ("Sobre os Fundamentos de uma Teoria do Estado"). Nele são tecidas reflexões iniciais sobre o papel do Estado em relação ao indivíduo, à economia e à religião, que seriam aprofundadas durante as três maiores reuniões do grupo, realizadas em Kreisau em maio e outubro de 1942 e junho 1943. Os resultados das discussões eram sintetizados em textos que assumiam uma função programática. É o caso, por exemplo, da ata redigida por Mierendorff após a última conferência em Kreisau, que estabelece um plano concreto de ações para o grupo, ou ainda do texto Bestrafung von Rechtsschändern ["Punição de Violadores do Direito"], que defendia a punição dos crimes nazistas após o fim da guerra e previa como seus perpetradores deveriam ser julgados. Por sua vez, o documento Grundsätze für die Neuordnung ["Fundamentos para a Nova Ordem"] apresenta ideias concretas do grupo para a reconfiguração política da Alemanha, tais como a definição do cristianismo enquanto base para a "renovação política e religiosa" do povo alemão, para o estabelecimento duradouro da paz e para a reconstrução da Alemanha no contexto de uma comunidade europeia.

Em 1943, alguns membros do Círculo de Kreisau decidiram envolver-se na conspiração ativa contra o regime. Adolf Reichwein e Julius Leber, entre outros, estabeleceram contato com opositores ligados ao exército, como Ludwig Beck, Carl Friedrich Goerdeler e Claus Schenk von Stauffenberg, que tomaram parte no plano que culminou no atentado cometido contra Hitler em 20 de julho de 1944, conhecido como "Operação Valquíria”. A Gestapo associou 
então o Círculo de Kreisau à tentativa de golpe empreendida pelos dissidentes do exército e a maioria dos membros do grupo foi presa e julgada não só pelas reuniões junto ao Círculo, mas também por uma suposta coparticipação no atentado contra Hitler. Oito integrantes foram condenados à morte, entre eles Helmuth James von Moltke, Peter Yorck, Alfred Delp, Adolf Reichwein e Julius Leber.

A correspondência entre Moltke e Freya é extensa e inclui o período em que Moltke esteve preso. Uma seleção de cinco cartas as revela como testemunho singular da Shoá e, por outro lado, como uma tentativa de preservar a própria memória diante dos filhos. Esse material permite desenvolver a ideia de que o tradutor pode assumir, em certa medida, a função de um editor.

\section{1.a) Cartas de 1941 e 1942: documentos da Shoá}

Em 05, 08 e 09 de novembro de 1941, Moltke escreveu três cartas à esposa. Na época, ele residia em Berlim, onde trabalhava como jurista especializado em direito internacional no Ministério de Relações Exteriores, e Freya permanecia na propriedade rural do casal, em Kreisau, com os dois filhos pequenos. Nas três cartas, assuntos como o mau tempo, o cardápio de um almoço com amigos, os afazeres no campo e preparativos para a ceia de Natal alternam-se com referências e posicionamentos de Moltke em relação a fatos históricos que marcaram o contexto em que elas foram escritas, como a guerra e a perseguição aos judeus pelo governo alemão. No primeiro parágrafo da carta de 05 de novembro de 1941, por exemplo, um comentário sobre o inverno rigoroso serve como metáfora ao prejuízo humano provocado pela guerra:

Um dia cinzento depois do outro: garoa, neva, derrete e congela de novo. Em Kreisau não deve estar diferente. Um horror. No front é a mesma coisa; não há geada, o que ainda seria suportável, somente um frio que não dissolve a sujeira, apenas esfria a lama. A guerra segue na mesma lentidão e, suponho eu, com o mesmo desgaste humano e 
material: muitos dos homens que retornarem, retornarão em um estado deplorável depois desse esgotamento absurdo. (Carta de Helmuth a Freya, 05/11/1941, Oppen 310). ${ }^{15}$

A carta continua com um relato sobre um almoço na casa de amigos do casal, em que um homem que havia estado com as tropas alemãs no Mar Báltico teria relatado "histórias macabras" da guerra e sido repreendido por Moltke: "Quando ele estava no auge das histórias, não aguentei mais ouvir e disse que não tínhamos o direito de falar nada a respeito, já que todos havíamos nos comportado da mesma forma". A carta volta então a assuntos triviais até o seguinte trecho, em que se relata um episódio de fornecimento clandestino de alimentos a um judeu conhecido pelo casal:

\begin{abstract}
Depois começou a confraternização com o seu rocambole de papoula, que foi recebido com aplausos; e ele estava mesmo especialmente saboroso. Embrulhei o que sobrou e vou levar hoje para o Unger. Ontem perguntei ao Steinke se eu poderia levar algumas coisas para o Unger, que está visivelmente magro, e ele acha que U. não iria recusar. Afinal é o último judeu que conheço, encaro isso como uma caridade e estou certo de que você aprova. Então vou levar hoje o resto do rocambole, um pouco de bacon e daqui a alguns dias levo 3 ou 4 ovos e maçãs. (Helmuth James von Moltke a Freya von Moltke, 05/11/1941. Oppen 310s.)
\end{abstract}

Para compreender o quanto o trecho da carta reproduzido acima pode ser considerado um documento de seu contexto histórico e de um gesto de resistência de Moltke, é preciso ter em mente que a perseguição aos judeus, iniciada com a ascensão de Hitler em 1933, vinha se radicalizando desde a noite de 9 de novembro de 1938, quando sinagogas foram incendiadas e lojas de judeus invadidas e saqueadas por toda a Alemanha. Em novembro de 1941, mui-

${ }^{15}$ Quando não houver outras indicações, as traduções das cartas são de autoria de Anna Carolina Schäfer.

Cad. Trad., Florianópolis, v. 41, no 3 p. 242-272, set-dez, 2021. 
tos judeus já haviam emigrado e buscado exílio em outros países ou sido deportados a campos de concentração. As grandes ondas de deportação haviam começado em outubro do mesmo ano. Em setembro, houve as primeiras execuções por gás em Auschwitz. Quem ousasse ajudar os judeus que ainda viviam na Alemanha - intenção relatada por Moltke na carta à esposa - colocava a si próprio em risco, uma vez que as leis de Nuremberg, promulgadas em 1935, e outras leis suplementares aprovadas nos anos seguintes previam punições severas aos "cidadãos alemães" que mantivessem relações pessoais com judeus.

Carta após carta, Moltke demonstra tomar conhecimento da perseguição dos judeus na Alemanha e busca formas concretas de agir contra ela. Ainda na carta de 05 de novembro, ele propõe à esposa a reintrodução do hábito da oração à mesa como forma de ensinar aos filhos pequenos a noção de igualdade entre as pessoas, rejeitada pela ideologia nazista de segregação. Como funcionário do Ministério das Relações Exteriores, Moltke combateu o decreto promulgado em 25 de novembro de 1941, que subtraía a nacionalidade alemã de judeus alemães residentes no exterior ou deportados e que confiscava seus bens em território alemão. Nas cartas enviadas em 08 e 09 de novembro de 1941, ele relata conflitos morais e embates travados com seus colegas de trabalho; nessas cartas usa pela primeira vez termos que denunciam abertamente os atos cometidos pelo Estado nazista contra os judeus, como "perseguição" e "assassinato".

Falta a esses homens uma percepção de universalidade, de que nenhuma ação se perde no universo, de que tudo está ligado, de que um assassinato em Varsóvia repercute em Calcutá e em Sidney, no Polo Norte e no Curdistão, e não se trata de repercussões políticas, mas sim morais. (Helmuth James von Moltke a Freya von Moltke, 08/11/1941. Oppen 313).

Ontem estive em uma reunião sobre perseguição aos judeus no Ministério de Relações Exteriores. Foi a primeira vez 
que me dediquei profissionalmente a essa questão. Bati de frente com 24 homens por reprovar, e por um momento até mesmo por conseguir deter um decreto que já havia obtido aprovação de todos os ministros e do chefe do Alto Comando do Exército. (Helmuth James von Moltke a Freya von Moltke, 08/11/1941. Oppen 313).

$\mathrm{Na}$ carta de 09 de novembro de 1941, Moltke menciona uma reunião com judeus no Ministério, sem especificar de quais "detalhes" foram tratados. $\mathrm{Na}$ forma como ele se refere a essas pessoas percebe-se seu distanciamento ideológico em relação ao nacionalsocialismo: ele usa, em alemão, a expressão "jüdische Menschen" (pessoas judias), distanciando-se assim da noção difundida pela propaganda nazista de que os judeus não seriam "pessoas", "seres humanos" (Menschen) mas uma espécie inferior ("subhomens" ou, em alemão, Untermenschen).

Passei a manhã com algumas pessoas judias que precisavam acertar detalhes antes de sua deportação. Nos últimos 3 dias mais umas dez mil receberam a ordem de ficarem de prontidão. Foi bonito ver como essas pessoas mantiveram uma postura firme e só posso desejar que não nos comportemos pior quando chegar a nossa vez. (Helmuth James von Moltke a Freya von Moltke, 09/11/1941. Oppen 315; grifos nossos)

Em outra carta, escrita no ano seguinte, e também iniciada com assuntos triviais como o inverno rigoroso. Moltke faz uma referência explícita ao extermínio de judeus na Polônia e à forma como os nazistas se desfaziam dos corpos, fatos dos quais ele declara já ter suspeitado, mas que agora teriam sido confirmados por um colega de trabalho:

$\mathrm{O}$ almoço de ontem foi interessante porque o homem com o qual eu almocei tinha acabado de chegar do Governo Geral na Polônia e relatou de forma verídica sobre o 'alto-forno 
da SS'. Até então eu não acreditava, mas ele me garantiu que é verdade: nesse forno são 'processadas' todos os dias seis mil pessoas. Ele esteve em um campo de prisioneiros distante dali e os oficiais desse campo lhe contaram isso com certeza. Além disso, eles contaram histórias realmente difíceis de acreditar sobre alguns dos senhores que trabalham ali. (Helmuth James von Moltke a Freya von Moltke, 10/10/1942. Oppen 420).

As quatro cartas de Moltke são testemunhos raros da Shoá. Ouve-se nessas cartas a voz de alguém que se opunha à perseguição e não presenciou a execução de judeus, mas que teve conhecimento dos fatos por meio de diferentes pessoas. Não se deve esquecer que, embora Moltke fosse funcionário do governo, ele se utilizou de seu cargo no ministério para facilitar a emigração de milhares de judeus a países onde estariam seguros. Também fez diversas viagens ao exterior e intermediou contatos entre judeus exilados e famílias que estavam prestes a deixar a Alemanha. As cartas da prisão dão igual testemunho de sua contraposição ao regime.

\section{1.b) Cartas da prisão}

Cartas como as de Moltke, em que se fala de forma relativamente aberta sobre crimes cometidos pelos nazistas e atos de resistência, constituem uma exceção. Conforme esclarecem KnoopGraf \& Jens a respeito das cartas escritas por Willi Graf, membro d' A Rosa Branca, "a vigilância crescente pelo Estado nacional-socialista tornava necessário camuflar comentários de teor político e crítico em parábolas e alusões inofensivas" (109). Se no cotidiano as cartas já estavam sujeitas à autocensura gerada pela simples possibilidade de elas serem interceptadas pelos órgãos nacional-socialistas de repressão, a partir do momento em que eram enviadas por um detento passavam a ser efetivamente lidas e controladas. Aos detentos era permitido escrever, via de regra, a cada duas semanas, em um formulário cedido pela penitenciária e, em geral, com 
as mãos algemadas, conforme revela o padre jesuíta Alfred Delp, preso com Moltke por seu envolvimento no Círculo de Kreisau, ao final de sua carta de despedida ao afilhado recém-nascido: "Escrevi isso de mãos algemadas. Não quero te deixar essas mãos algemadas como legado; mas a Liberdade que sustenta essas algemas e que dentro delas se mantém fiel a si mesma, que ela te seja dada da forma mais bela, mais suave e mais segura." (Alfred Delp a Alfred Sebastian Keßler, 23/01/1945. Bleistein 142).

Qualquer palavra ou crítica expressa em cartas redigidas por prisioneiros poderia se voltar contra o autor ou remetente da carta ou impedir que esta chegasse a seu destino. Assim se explica a ausência de referências ou críticas ao nacional-socialismo ou às ações de resistência, em cartas escritas da prisão. Uma exceção, como se mencionou, é a extensa correspondência trocada entre Helmuth e Freya von Moltke ao longo dos cinco meses em que ele esteve detido na penitenciária de Tegel, em Berlim.

Quando Moltke foi transferido para a penitenciária de Tegel, o capelão responsável pelos presos luteranos era Harald Poelchau, um conhecido de Moltke que havia participado de diversas reuniões do Círculo de Kreisau, mas nunca fora descoberto pela Gestapo. Além de transmitir mensagens de Moltke a amigos do Círculo de Kreisau que se encontravam nas celas vizinhas (Alfred Delp e Eugen Gerstenmaier), Poelchau passou a transportar quase diariamente, no bolso de sua jaqueta, cartas de Moltke para Freya e vice-versa. Ele levava as cartas de Moltke até a própria casa, onde Freya as lia e respondia. Depois, Poelchau levava as cartas para a antiga secretária de Moltke, Katharina Breslauer, que as guardava em segurança até que Freya pudesse levá-las a Kreisau. Lá permaneceram escondidas em colmeias desativadas até que Freya as levasse consigo ao deixar a Alemanha, no outono alemão de 1945 (Cf. Moltke e Moltke 16s).

As 172 cartas trocadas pelo casal podem ser consideradas um projeto epistolar com o intuito de resgatar e fazer justiça à memória de Moltke, sobretudo perante seus filhos, uma vez que ele fora condenado à morte por enforcamento como traidor da pátria. Especialmente comovente e representativa dessa intenção é a carta de des- 
pedida enviada por Moltke aos filhos em 11 de outubro de 1944. É perceptível sua preocupação em explicar suas motivações para combater o nacional-socialismo e em se distanciar ideologicamente dos responsáveis pelo atentado cometido contra Hitler em 20 de julho de 1944. Moltke afirma discordar veementemente de ações violentas como as que foram colocadas em prática por alguns outros membros do Círculo de Kreisau envolvidos no planejamento do atentado:

O motivo pelo qual serei morto vai entrar para a história, e ninguém sabe como. Mas quero dizer-lhes o seguinte: por toda minha vida, desde a escola, combati um espírito de mesquinhez e violência, de presunção e falta de respeito ao próximo, de intolerância e de intransigência absoluta e impiedosa que existe nos alemães e encontrou sua expressão no Estado nacional-socialista. Também me esforcei para que esse espírito, com todos os seus efeitos terríveis, como nacionalismo exacerbado, a perseguição racial e incredulidade fossem superados. Então, sob o ponto de vista nacional-socialista serei morto justamente. Mas nunca desejei ou incentivei atos violentos como o atentado de 20 de julho, pelo contrário, eu os combati, pois, por diversas razões, desprezava tais medidas e acima de tudo acreditava não ser esse o caminho para eliminar a raiz do mal espiritual. Sob esse ponto de vista serei morto injustamente. Ninguém pode dizer ainda como isso tudo será visto no futuro, nem se a minha participação nessas ações continuará sendo considerada importante. Só quero que vocês saibam que não sou da mesma laia que os homens do 20 de julho. (Helmuth James von Moltke aos filhos Caspar e Konrad, 11/10/1944. Moltke e Moltke 63).

A preservação das cartas por Freya e o desejo de resgatar a memória do marido, bem como a tentativa de oferecer aos filhos a própria versão dos acontecimentos, por parte de Moltke, devem ser considerados no contexto da época: os Moltke compreendiam que, até que as sentenças penais dadas pelos tribunais nacional-socialistas fossem revogadas, os membros da resistência seriam considera- 
dos criminosos do ponto de vista judicial ( $C f$. Salgado e Reichmann 25). As cartas, porém, documentam claramente que, mesmo frente à repressão e à morte iminente e, além disso, frente à difamação póstuma, Moltke não renunciou à convicção de ter agido corretamente e combatido o nazismo; ele também encoraja a esposa e os filhos a seguirem as próprias convicções. Assim, por ter escapado à censura e ter sido preservada, a correspondência entre Moltke e a família constitui um material de pesquisa precioso.

\title{
3. Problemas e estratégias de tradução e edição de cartas
}

\begin{abstract}
Às vezes eu reflito sobre o destino nas nossas longas conversas por cartas. Pergunto-me se daqui a 10, 20 ou mais anos elas ainda serão um material digno de ser lido por você e por nossos filhinhos. Elas nasceram de uma situação que possivelmente só terá sido registrada por escrito raras vezes, porque o contato era então interrompido ou controlado. Quando esse tempo tiver passado, no dia em que houver de novo uma verdadeira Paz, o que se dirá sobre tais ponderações? Será que vão compreendê-las? (Carta de Helmuth a Freya, 02/01/1945. Moltke e Moltke 250).
\end{abstract}

A carta de Moltke aponta - por motivos claros - para a diferença entre os contextos comunicativos de produção das cartas e de sua recepção futura. Se Moltke duvidava de que as cartas seriam lidas pelos próprios filhos, mal poderia imaginar que um dia integrariam um projeto brasileiro de tradução de cartas de membros da resistência. Mas é interessante notar que, também no contexto de partida, se percebe um dos problemas de tradução que Christiane Nord (352) enumerou com relação a quaisquer gêneros textuais.

Nord descreve quatro categorias de problemas de tradução: i) os pragmáticos, que decorrem das diferenças entre situações comunicativas de texto de partida (TP) e texto de chegada (TC) e estão, portanto, relacionados a fatores extratextuais; ii) problemas 
específicos do par cultural, pautados nas diferenças entre as normas e convenções das duas culturas envolvidas no processo tradutório; iii) problemas específicos do par linguístico, que estão ligados a lacunas de equivalência entre as línguas de partida e de chegada e se relacionam aos fatores internos da análise textual e iv) problemas específicos de um texto, cuja solução não é facilmente aplicável a outras tarefas de tradução por dizerem respeito a características textuais e formas de expressão únicas, bem como a estilos individuais.

Nas cartas de Moltke, por exemplo, seria possível citar as diversas referências a elementos da realidade da época e a presença de palavras características da linguagem nacional-socialista $(C f$. Klemperer) como problemas pragmáticos no nível do léxico. Já as fórmulas de saudação e despedida podem ser consideradas tanto problemas específicos do par cultural, por estarem ligadas a convenções do gênero textual "carta" em ambas as culturas, quanto a problemas específicos do par linguístico alemão-português, uma vez que não há em português tantas fórmulas diversas de despedida como em alemão. O mesmo vale para as formas de tratamento, que atendem a convenções culturais e linguísticas distintas em alemão e português. Por fim, o "tom" das cartas, determinado, entre outros fatores, pelo estilo pessoal do remetente e por sua relação com o destinatário, pode ser considerado um exemplo de problema de tradução específico do texto.

Nord defende que os problemas sejam resolvidos em um processo de tomada de decisão do tipo top-down, que parte do nível pragmático, em que o tradutor decide qual função (documental ou instrumental) a tradução assumirá no contexto de chegada e, consequentemente, quais elementos do texto de partida poderão ser reproduzidos como tais e quais precisarão ser adaptados aos conhecimentos prévios, às necessidades comunicativas e às expectativas do destinatário, bem como às restrições de meio na cultura de chegada.

Assim o modelo de Nord fornece uma base consistente para a solução de cada problema tradutório e, à medida que individualiza as decisões a serem tomadas pelo tradutor, abre a possibilidade de ele, diante de cada problema específico, tomar uma decisão estran- 
geirizante, reproduzindo elementos da cultura e língua de partida, ou adaptante, voltando-se à língua e cultura de chegada. Tal flexibilidade é especialmente importante quando a função da tradução como um todo, como é o caso da tradução das cartas, não é puramente documental ou instrumental, mas sim híbrida, o que exige por si só que se opte ora por um lado e ora por outro do modelo.

No caso da tradução de cartas de membros da resistência alemã, o tradutor talvez precise ainda estender sua função a campos que, normalmente, seriam da alçada de um editor. $\mathrm{O}$ caráter lacunar das cartas, por exemplo, exige decisões de caráter mais estrangeirizante, voltadas à contextualização do texto, como a inserção de notas, paratextos e imagens (como fotos, cartazes de época, fac-símiles) na tradução, seja ela uma tese ou um futuro livro. Tais inserções contribuem para que se recrie parte da materialidade da carta em alemão, já que outros elementos importantes para sua interpretação, como a caligrafia, o tipo de papel em que foi escrita, o tipo de envelope, não podem ser "traduzidos". Por outro lado, foram tomadas decisões mais adaptantes, não somente pela preocupação de não criar estranhamento, mas porque a tradução desse tipo de material também deseja despertar a empatia do leitor brasileiro com relação às cartas traduzidas e aos membros da resistência. Com esse intuito, optou-se por não recriar uma linguagem de época, que talvez soasse formal demais nos dias de hoje, por utilizar sempre o "você" como forma de tratamento e por buscar o equivalente funcional mais próximo em português na tradução de fórmulas de despedida.

O maior desafio foi, sem dúvida, encontrar o "tom" certo para cada carta, de tal forma que a empatia para com os remetentes não faça o leitor perder de vista o valor histórico dos textos que tem diante de si. Para tanto, foi preciso analisar caso a caso as variáveis que determinam a produção de tal correspondência: os traços conhecidos da personalidade do remetente, o tipo de relação com o destinatário, o momento em que a carta foi enviada, e as condições em que foi escrita (na prisão ou não, sob vigilância ou não, na possibilidade ou não de censura). 
Na carta citada acima, Moltke questionava se, em 10 ou 20 anos, as cartas seriam "dignas" de serem lidas. Feita a opção de traduzi-las mesmo após 75 anos, o tradutor acaba assumindo funções exercidas em geral por um editor. Mas até onde vão suas funções nesse sentido? É sabido que, no caso da tradução d'A rosa branca, de Inge Scholl, tratava-se de um projeto acadêmico que, ao longo do tempo, revelou potencial para ser publicado ( $C f$. Perez e Reichmann). Ao propor a publicação do livro a uma editora de São Paulo, o grupo de tradutores atuou, por assim dizer, como agente literário, e as etapas editoriais subsequentes foram assumidas pela editora. O mesmo pode acontecer - e talvez devesse acontecer com mais frequência - com relação a outras obras: o tradutor, por conhecer outro(s) idioma(s) e estar em contato com outra(s) cultura(s), pode trazer à luz obras que são relevantes para a cultura de chegada e que por diversos motivos ainda não foram identificadas por agentes literários ou editoras; em casos ideais, pode também dar início a coleções ou séries, caso uma editora tenha abertura para tanto.

$\mathrm{Na}$ fase de produção editorial, a depender da filosofia de cada editora, o tradutor pode sugerir a inclusão de notas, prefácio ou posfácio, contribuir para a definição do título do livro traduzido, interagir com revisores (para validar ou não uma revisão proposta) e diagramadores (para tratar de questões técnicas como a transcrição, transliteração ou hifenização de palavras ou nomes estrangeiros ou de decisões relacionadas ao layout ou às cores da capa do livro); também pode se comunicar com leitores que escrevem cartas à editora com dúvidas ou comentários que eventualmente se referem à tradução e levam a revisões em edições posteriores.

Imagina-se aqui, sem dúvida, uma relação profissional madura e de confiança mútua entre tradutor e editora. Tais tarefas foram abordadas por outros estudiosos da vertente funcionalista até antes de Nord, como Holz-Mänttäri. A autora situa a tradução (não literária) em um contexto sociocultural, o que também inclui a interação entre o tradutor e o cliente. Em sua concepção, o tradutor profissional exerceria o papel de "especialista na comunicação intercultural, com a tarefa de produzir 'portadores de mensagem' 
capazes de transmitir uma mensagem para além das fronteiras culturais" ( $C f$. Moreira 38, tradução do autor). Trata-se de um “especialista na produção de textos" (id.) que assume a responsabilidade pelo produto final:

O processo tem início quando o tradutor recebe de seu cliente a tarefa de traduzir, o material textual a ser traduzido e informações sobre o objetivo do texto no futuro contexto de recepção. De posse dessas informações, ele especifica o produto final e mobiliza os meios necessários para a realização do trabalho. Snell-Hornby (2006) observa que o trabalho do tradutor é representado como um sistema de cooperação entre indivíduos, no qual tomam parte o cliente, o produtor do texto de partida e o receptor do texto de chegada, além, é claro, do tradutor. (Moreira 38)

Umberto Eco, que analisa aspectos teóricos da tradução a partir da perspectiva do autor traduzido, e que sempre prezou por interagir com seus tradutores, concebe a tradução (literária) como um processo complexo de negociação, seja com o autor do texto de partida, com o texto de partida em si e com editores, revisores e leitores:

In this kind of negotiation there may be many parties: on one side, there is the original text, with its own rights, sometimes an author who claims right over the whole process, along with the cultural framework in which the original text is born; on the other side, there is the destination text, the cultural milieu in which it is expected to be read, and even the publishing industry, which can recommend different translation criteria, according to whether the translated text is to be put in an academic context or in a popular one. [...] A translator is the negotiator between those parties, whose explicit assent it not mandatory. There is an implicit assent even in the reading of a novel or of a newspaper article, as in the former case the reader implicitly subscribes a suspension of disbelief, and in the latter relies on the silent 
convention that what is said is guaranteed to be true. (Eco 6 , grifo no original).

Os projetos de tradução iniciados no âmbito acadêmico não partem da certeza da publicação, nem se baseiam em contratos firmados com um "cliente". O "cliente" é hipotético, bem como o público em potencial. Se esta condição cria inseguranças ao tradutor, cria também um espaço amplo de criatividade e responsabilidade quanto às decisões a serem tomadas: aqui o tradutor é de fato seu próprio editor. É ele quem seleciona os textos, os analisa de forma criteriosa, estrutura as traduções, redige todos os paratextos, cria a forma ideal de apresentação da tradução ao seu leitor e é, enfim, responsável pelo "produto final". O produto final, quando se trata da tradução de cartas de membros da resistência alemã ao nazismo, pode abrir a discussão sobre um tema importante, comovente e pouquíssimo conhecido no Brasil.

\section{Referências}

Alfred Delp. Gesammelte Schriften. Band IV - Aus dem Gefängnis. Editado por Roman Bleistein. Josef Knecht: Frankfurt a. M., 1985, pp. 139-142.

Alonso, Raíssa. Ecos da resistência ao Nazismo: Movimento dos Alemães Livres e Associação Democrática Alemã. São Paulo (1933-1950). (Dissertação de mestrado). Faculdade de Filosofia, Letras e Ciências Humanas, Universidade de São Paulo. São Paulo, 2019. (31/08/20) DOI: https://doi.org/10.11606/D.8.2019. tde-11122019-161934.

Beltrán Almería, Luís. "Las estéticas de los géneros epistolares". Anuario de la Sociedad Española de Literatura General y Comparada. Vol. X (1996): 239-246. (06/06/20). Disponível em: http://www.cervantesvirtual.com/nd/ark:/59851/ bmc9g605. 
Bonhoeffer, Dietrich. Resistência e submissão. Cartas e anotações escritas na prisão. Traduzido por Nélio Schneider. São Leopoldo: Sinodal, 2003.

Cox, John M. Circles of Resistance: Jewish, Leftist, and Youth Dissidence in Nazi Germany. Peter Lang: New York, 2009.

Diaz, Brigitte. O gênero epistolar ou o pensamento nômade. Formas e funções da correspondência em alguns percursos de escritores do século XIX. São Paulo: Edusp, 2016.

Distel, Barbara. "Widerstand der Verfolgten". Lexikon des deutschen Widerstandes. Wolfgang Benz e Walter H. Pehle (Eds.). Frankfurt a. M.: Fischer, 2008. pp. 112-126.

Eco, Umberto. Mouse or Rat? Translation as negotiation. Londres, Phoenix, 2003.

Foucault, Michel. "A escrita de si”. O que é um autor? Trad. António Fernando Cascais e Eduardo Cordeiro. Lisboa: Passagens. 1992. pp. 129-160.

Hudemann, Rainer. "A Rosa Branca no contexto da resistência alemã durante o 'Terceiro Reich'”. A Rosa Branca, de Inge Scholl. Juliana P. Perez e Tinka Reichmann (Eds.). Traduzido por Anna C. Schäfer et al. $2^{\mathrm{a}}$. ed., $1^{\mathrm{a}}$ reimpressão. São Paulo, Editora 34, 2020, pp. 239-258.

Klemperer, Klemens von. "Vorwort". Mit dem Mut des Herzens. Die Frauen des 20. Juli. Dorothee von Meding (Ed.). Berlim: Goldmann Verlag, 1997.

Klemperer, Vitor. LTI: A linguagem do Terceiro Reich. Traduzido por Miriam Bettina Paulina Oelsner. São Paulo: Contraponto, 2010.

Graf, Willi. Briefe und Aufzeichnungen. Knoop-Graf, Annelise; Jens, Inge. (Ed.) Frankfurt a. M., Fischer, 2004.

Moltke, Helmuth Caspar von e Moltke, Ulrike von. (Eds.) Helmuth James und Freya von Moltke. Abschiedsbriefe Gefängnis Tegel. September 1944 - Januar 1945. München: C.H. Beck, 2013. 
Mommsen, Hans. "Der Widerstand gegen Hitler und die deutsche Gesellschaft". Alternative zu Hitler. Studien zur Geschichte des deutschen Widerstandes. München: Beck, 2000, pp. 29-52.

Mommsen, Hans. "Bürgerlicher (nationalkonservativer) Widerstand". Lexikon des deutschen Widerstandes. Wolfgang Benz e Walter Pehle (Eds.). Frankfurt a. M.: Fischer, 2008, pp. 55-67.

Moreira, Marcelo Victor de Souza. Estudos Funcionais da Tradução: rupturas $e$ continuidade. (Tese de doutorado). Faculdade de Filosofia, Letras e Ciências Humanas, Universidade de São Paulo. São Paulo, 2014. (16/09/20) DOI: 10.11606/D.8.2017.tde-26102017-145134 Disponível em: https://www.teses. usp.br/teses/disponiveis/8/8144/tde-26102017-145134/pt-br.php.

Müller, Wolfgang. "Brief". Handbuch der literarischen Gattungen. Dieter Lamping (Ed.). Stuttgart: Alfred Kröner, 2010, pp. 75-83.

Nord, Christiane. "Textanalyse: pragmatisch/ funktional". Handbuch Translation. Mary Snell-Hornby et al (Eds.). Tübingen: Stauffenburg, 2006. pp. 350-351.

Oppen, Beate Ruhm von (Ed.). Helmuth James von Moltke. Briefe an Freya. 1939-1945. München: C.H. Beck, 2007.

Petrescu, Corina. Against all Odds. Models of Subversive Spaces in National Socialist Germany. Frankfurt a. M.: Peter Lang, 2010.

Reichmann, Tinka; Schäfer, Anna Carolina; Salgado, Janaina Lopes. “'A Rosa Branca": Contribuições da tradução para a difusão de fontes sobre a resistência antinazista”. Graphos, v. 18, (2016): 68-88, 2016. (15/08/2020). Disponível em: https://periodicos.ufpb.br/index.php/graphos/article/view/32162.

Rollenberg, Denise. "Definir o conceito de resistência: dilemas, reflexões, possibilidades". História e memória das ditaduras do século XX. Samantha Viz Quadrat e Denise Rollemberg (Eds.). Vol.1. São Paulo: FGV, 2015.

Salgado, Janaina Lopes; Reichmann, Tinka. "Injustiça na justiça no nazismo: relatos de sobreviventes da Rosa Branca". Tradução em Revista. Fascículo 21 (2016/2): 24-45. Rio de Janeiro: PUC. (31/08/20) DOI: 10.17771/ 
PUCRio.TradRev.2802. Disponível em: https://www.maxwell.vrac.puc-rio. $\mathrm{br} / 28027 / 28027$. PDFXXvmi $=$.

Salgado, Janaina Lopes. A Rosa Branca e a correção da (in)justiça nacionalsocialista no Pós-guerra: interface entre história, direito e tradução. (Dissertação de mestrado). Faculdade de Filosofia, Letras e Ciências Humanas, Universidade de São Paulo. São Paulo, 2017. (31/08/20) DOI: 10.11606/D.8.2017.tde-26102017145134 Disponível em: https://www.teses.usp.br/teses/disponiveis/8/8144/tde26102017-145134/pt-br.php.

Sales, Maria Visconti. "Não nos calaremos, somos a sua consciência pesada; a Rosa Branca não os deixará em paz". A Rosa Branca e sua resistência ao nazismo (1942-1943). (Dissertação de Mestrado). Universidade Federal de Minas Gerais, Belo Horizonte, 2017. (31/08/20) Disponível em: < http://hdl.handle.net/1843/ BUBD-AUTHBV $>$.

Schäfer, Anna Carolina. Quando a tradução (re)conta a história: os interrogatórios da Rosa Branca. (Dissertação de mestrado). Faculdade de Filosofia, Letras e Ciências Humanas, Universidade de São Paulo. São Paulo, 2015. (31/08/20) DOI: <10.11606/D.8.2015.tde-23112015-133329>. Disponível em: https:// www.teses.usp.br/teses/disponiveis/8/8144/tde-23112015-133329/pt-br.php.

Schlinzig, Marie Isabel. Abschiedsbriefe in Literatur und Kultur des 18. Jahrhunderts. Berlin; Boston: De Gruyter, 2012.

Scholl, Inge. A Rosa Branca: a história dos estudantes alemães que desafiaram $o$ nazismo. $2^{\mathrm{a}}$. ed., $1^{\mathrm{a}}$ reimpressão, editado por Juliana P. Perez e Tinka Reichmann. Traduzido por Anna C. Schäfer et al. São Paulo, Editora 34, 2020.

Stauf, Renate; Simonis, Annette; Paulus, Jörg (eds.). Der Liebesbrief. Schriftkultur und Medienwechsel vom 18. Jahrhundert bis zur Gegenwart. . Berlin, New York: de Gruyter, 2008.

Stuiber, Irene. "Kreisauer Kreis". Enzyklopädie des Nationalsozialismus. Benz, Wolfgang et al. (Eds.). Stuttgart: Deutscher Taschenbuch Verlag, 2007. pp. 606-607.

Utida, Yasmin Cobaiachi. Tradução e memória: a legendagem de um filme-testemunho sobre a Rosa Branca. (Dissertação de mestrado). Faculdade de Filosofia, Letras e 
Ciências Humanas, Universidade de São Paulo. São Paulo, 2017. (31/08/20) DOI: 10.11606/D.8.2017.tde-03042017-115923. Disponível em: https://www.teses.usp. br/teses/disponiveis/8/8144/tde-03042017-115923/pt-br.php.

Weil, Simone. O enraizamento. São Paulo: EDUSC, 2001.

\section{Resenhas:}

Araújo, Ignácio. "Longa sobre nazismo omite povo alemão". Folha de São Paulo, 29/10/2005. Ilustrada. (Acesso em 22/08/20) Disponível em: https:// www1.folha.uol.com.br/fsp/ilustrad/fq2910200520.htm.

"Uma mulher contra Hitler estreia no Brasil". O Estado de São Paulo, 24/02/2006. Cultura. (Acesso em 22/08/20) Disponível em: https://cultura.estadao.com.br/ noticias/cinema,uma-mulher-contra-hitler-estreia-no-brasil,20060224p1785

\section{Filmografia}

Die Weiße Rose. Direção: Michael Verhoeven. Roteiro: Michael Verhoeven e Mario Krebs. Alemanha: TeleCulture, 1982.

Sophie Scholl. Die letzten Tage Direção: Marc Rothemund. Alemanha: Entertainment $\mathrm{GmbH}, 2005$. Tradução brasileira: Uma mulher contra Hitler.

Recebido em: 12/04/2021

Aceito em: 29/07/2021

Publicado em setembro de 2021

Anna Carolina Schäfer. E-mail: annacarolschaefer@hotmail.com. ORCID: https://orcid.org/0000-0002-2824-3130.

Juliana Pasquarelli Perez. E-mail: julianaperez@usp.br. ORCID: https://orcid. org/0000-0002-8159-1978.

Tinka Reichmann. E-mail: tinka.reichmann@uni-leipzig.de ORCID: https:// orcid.org/0000-0003-1320-3045 